\title{
Side-effects from imatinib treatment of advanced GIST-associated with a better outcome
}

\author{
J Åhlén ${ }^{1,2^{*}}$, J Westerdahl', J Zedenius' ${ }^{1}$, R Bränström ${ }^{1}$, C Larsson ${ }^{1,2}$ and I-L Nilsson ${ }^{1}$
}

\begin{abstract}
Background: Imatinib is considered to be the first-line therapy for patients with unresectable and/or metastatic gastrointestinal stromal cell tumors (GIST). The aim of this study was to analyze the occurrence of side-effects and clinical outcome.

Materials \& Methods: 75 consecutive patients ( $41 \widehat{\jmath}$; median age 62 years, range 34-82), with GIST, who had received pre- and/or postoperative imatinib, were retrospectively reviewed. Chi-square test was used to compare the occurrence and distribution of side-effects and the KaplanMeier method was applied for survival analysis.

Results: The median follow-up time from the initiation of imatinib treatment was 48 months (4-107); median size of tumor was $10.3 \mathrm{~cm}$ (2.5-28) $\mathrm{cm}$. Moderate to severe or life-threatening toxic reactions from imatinib treatment were registered in 30/75 patients (17/34우). Most of the side-effects occurred early, 18/30 within the first month of imatinib treatment. Life-threatening complications occurred in two cases: agranulocytosis and tumor perforation. For the group of patients with metastatic or recurrent GIST ( $n=34$ ), presence of side-effects and female gender were associated with increased recurrence-free survival $(P=0.01)$.

Conclusions: Our findings indicate that side-effects from imatinib treatment are common. Their occurrence may be associated with a better outcome for patients with GIST.
\end{abstract}

Keywords: GIST, imatinib, side-effects, outcome

\section{Introduction}

Gastrointestial stromal cell tumor (GIST) is the most common mesenchymal tumor of the gastrointestinal tract. The prevalence is 7-15/100 000 , and about $50 \%$ are localized at the time of diagnosis [1,2].GISTs are resistant to conventional chemotherapy and radiation and the risk of localized peritoneal or metastatic relapse after tumor resection is high [3-6] All GISTs should be considered as potentially malignant; the standard treatment is complete tumor resection with negative tumor margins [7]. However, in many cases surgery alone is not curative. One in two patients with GIST will relapse after complete tumor resection, underlining the need for adjuvant medical treatment [5].

Mutations of the KIT proto-oncogene are central in the pathogenesis of GIST and the tumors are most often characterized by strong immunoreactivity to the KIT protein, the CD117 antigen [8-10]. The introduction of inhibitors of KIT tyrosine kinase has resulted in significantly improved outcomes of patient with advanced GIST. Imatinib mesylate is the tyrosine kinase blocker approved as the first-line treatment for patients with unresectable and/or metastatic GIST and for adjuvant treatment of patients with a significant risk of relapse [11-13]. Neoadjuvant (also called downstaging) treatment with imatinib may permit organ preservation and admit the possibility of radical margins of nonresectable GIST [14,15]. Adjuvant treatment offers improve-

Correspondence: jan.ahlen@karolinska.se

${ }^{1}$ Endocrine Surgery Unit, Karolinska University Hospital P9:03, SE-171 76 Stockholm, Sweden.

Full list of author information is available at the end of the article ment in progression-free survival [13]. In addition, subsets of patients are treated with imatinib in a palliative or recurrent disease setting. Since the outcome seems to be improved by an extended treatment period, patients with a high risk of GIST relapse will be treated with imatinib for many years.

Although the medication is generally well tolerated, virtually all patients will have at least one adverse event [16]. Doubling the dosage of imatinib from the standard level ( $400 \mathrm{mg}$ daily) to a high dose (400 mg twice daily) increases the incidence of severe adverse events $[13,17]$. However, no correlation could be seen between imatinib plasma trough level and previous grade 3 to 4 toxicity in patients taken a standard dose of $400 \mathrm{mg}$ daily, but there was a significant correlation to plasma albumin and creatinine clearance [18]. Low plasma concentrations of imatinib have been associated with a shortened time to disease progression [19]. Determination of the plasma concentration of imatinib is still not used routinely in clinical practice and the only practical guideline for interpreting the concentration is the recommendation to keep it above 1,100 ng/mL. Adverse effects may reduce the patient's adherence to treatment; discontinuation of imatinib treatment has been reported to result in rapid tumor progression in patients with advanced GIST [20].

The aim of this study was to evaluate the occurrence and the prognostic significance of side-effects from imatinib treatment. For this purpose a single-center cohort of GIST patients was retrospectively reviewed concerning tumor characteristics, treatment and side effects, in relation to disease recurrence and survival during follow-up. 


\section{Materials and Methods Cases}

The records of 75 consecutive GIST patients who received imatinib treatment at the Karolinska University Hospital, Sweden were retrospectively reviewed. All patients had been subjected to surgery and the initiation of imatinib treatment between February 2002 and July 2010. The study was approved by the ethical committee at the Karolinska University Hospital, Stockholm, Sweden.

The clinical data are summarized in Table 1. The radicality of the surgical resection and margins was classified as radical surgery with tumorfree resection margin (R0); intralesonal surgery with microscopic infiltration of the resection margin (R1) or tumor reduction with gross residual disease (R2). The GIST diagnosis was established according to consensus criteria [9]. Immunohistochemical analysis of CD117 was performed in routine histopathology for all cases. Data from mutational analyses of the KIT gene exon 9, 11, 13 and 17, and the PDGFRA gene exon 12 and 18 in routine histopathology were retrieved where available. The risk of recurrence was defined using the modified classification of Fletcher-Mietinen, based on primary tumor size, location and mitotic index [21] (Joensuu, 2008). Tumor size was estimated on the radiological view if the imatinib treatment was initiated preoperatively, and on the histopathological measurement for cases only treated postoperatively. The observed tumor sizes ranged from $2.5 \mathrm{~cm}$ to $28 \mathrm{~cm}$ and were subgrouped as $<5 \mathrm{~cm}, 5-10 \mathrm{~cm}$, or $>10 \mathrm{~cm}$ (Table 1). The primary tumor locations were esophagus $(n=2)$, stomach (34), duodenum (7), small intestine (24), colorectal (7) or uncertain (1). The mitotic index of tumors was defined as the number of mitoses per 50 high-power fields (HPF). Sixty-nine patients fulfilled the criteria of high risk, i.e. risk intestinal tumors with tumor size $\geq 5 \mathrm{~cm}$ or $\geq 5$ mitoses $/ 50 \mathrm{HPF}$ and gastric tumors with tumor size $\geq 10 \mathrm{~cm}$ or $\geq 5$ mitoses/50 HPF). The other six patients were classified as intermediate risk i.e. intestinal tumors with tumor size $2-5 \mathrm{~cm}$ or $\leq 5$ mitoses/50 HPF and gastric tumors with tumor size $5-10 \mathrm{~cm}$ or $\leq 5$ mitoses/50 HPF.

Metastatic spread was observed of peritoneal, hepatic, or pleural types. Metastatic or recurrent disease was diagnosed before initiation of imatinib therapy in 31 cases; another 3 cases were defined to have metastatic disease as a consequence of earlier invasive procedures (exploratory laparotomy with open biopsy or external drainage).

The imatinib treatment groups are presented in Figure 1. Imatinib treatment initiated preoperatively with the intention of later radical surgical removal of tumor including any metastatic disease was defined as neoadjuvant, and the corresponding treatment initiated postoperatively was defined as adjuvant. Treatment initiated after radically intended surgery for recurrent disease and palliative treatment were grouped separately. Forty-one patients without metastatic disease received neoadjuvant or adjuvant imatinib due to high or intermediate risk GIST. Another 34 patients with metastatic disease received imatinib in a neoadjuvant, palliative, recurrent disease or adjuvant setting. Twenty patients received neoadjuvant treatment for a median of 7 months (range 5 days-23 months) preoperatively. Plasma concentrations of albumin and creatinine prior to start of imatinib treatment have been used in the calculations and renal function (creatinine clearance) was estimated using Cockroft-Gault's formula: (140-age)*(weight/ creatinine)*(1.23 in men or 1.04 in women). Eight patients had no available recorded weight before initiation of imatinib treatment but all of them had creatinine within normal range (Table 1). The history of moderate to severe or life-threatening side-effects were classified according to Common Terminology Criteria for Adverse Events v4.0 (CTCAE) by which side effects are classified as grade 1 (mild), grade 2 (moderate), grade 3 (severe), grade 4 (life threatening) or grade 5 (death related to adverse effects). All patients were followed-up routinely for tumor recurrence by means of abdominal cross-sectional imaging (computed tomography, MRI or ${ }^{18}$ Fluorodeoxyglucose positron emmision tomography). Tumor response was evaluated by FDG-PET (11 cases in the neoadjuvant group) and/or contrast-enhanced computed tomography ( $n=75)$ and histopathological examination of the excised tumor $(n=75)$. Followup was defined as time from initiation of imatinib treatment to last documentation of state [no evidence of disease (NED), evidence of disease (ED) or death].

\section{Statistics}

Statistical analysis was performed with the PASW for Windows statistical package (18.0; PASW Inc., Chicago, IL). Recurrence-free survival was measured from the start of imatinib treatment to the time of first recurrence or most recent follow-up or death, tested with the log rank test and plotted by the Kaplan-Meier method. Pearson's Chi-square test was used to compare the distribution of patient and tumor characteristics between groups; $P<0.05$ was considered to be statistically significant.

\section{Results \\ Imatinib treatment and side effects}

The median follow-up time from the initiation of imatinib treatment until the last examination or death was 48 months (4-107; Table 1). Moderate to severe or life-threatening toxic reactions from imatinib treatment were registered in 30/75 patients (17/34ㅇ, Table 2, Supplemental Table A). There was no statistically significant difference in the prevalence of side-effects between patients with or without metastatic disease $(P=0.78)$, or between different groups of treatment settings ( $P=0.44$, Figure 1$)$, neither did we find any differences in relation to gender distribution $(P=0.11)$ or to age at the initiation of imatinib treatment $(P=0.45)$ (Figure 1, Table 2). Life-threatening complications occurred in two cases treated for metastatic GIST (Table 2). In Case no 29 the imatinib treatment was discontinued following development of agranulocytosis and sepsis. Case no 19 developed tumor perforation and was operated acutely, without interruption of imatinib treatment. In the other 28 patients, the most common side-effects were dermatitis/rash ( $n=15)$, gastrointestinal (9), edema (7), and muscle cramps (4). Fatigue was observed twice, and in addition several other side effects were noted in single patients.

Most of the side-effects occurred early, 18/30 within the first month of imatinib treatment. In 9 cases (Case number 5-8, 10, 12, 14, 29 and 30 , Table 2), the imatinib treatment was interrupted within 3 months because of one or more of the following side-effects: agranulocytosis with sepsis ( $n=1)$, dermatitis, rash (6), pruritus (2), edema (2), nausea, diarrhea (3), myalgia and muscle cramps (1). 
Table 1. Summary of clinical characteristics for all patients.

\begin{tabular}{|c|c|c|c|}
\hline Parameter (informative $\mathbf{n}=$ ) & $\begin{array}{l}\text { No metastatic } \\
\text { disease } \\
n=41\end{array}$ & $\begin{array}{c}\text { Metastatic or } \\
\text { recurrent disease } \\
\mathbf{n}=34\end{array}$ & $\begin{array}{l}\text { All GIST } \\
\text { cases } \\
\mathbf{n}=75\end{array}$ \\
\hline \multicolumn{4}{|l|}{ Gender $(n=75)$} \\
\hline Female / Male & $17+/ 24 \hat{\jmath}$ & $17+/ 17 \hat{\jmath}$ & $34+141 \overbrace{}^{\lambda}$ \\
\hline \multicolumn{4}{|l|}{ Age at start of imatinib $(n=75)$} \\
\hline Median years $(\min -\max )$ & $62(34-82)$ & $61(38-82)$ & $62(34-82)$ \\
\hline \multicolumn{4}{|l|}{ Patient weight $(n=67)$} \\
\hline Median kg (min-max) & $75(45-97)$ & $72(56-95)$ & $73(45-97)$ \\
\hline \multicolumn{4}{|l|}{ BMI $(n=65)$} \\
\hline 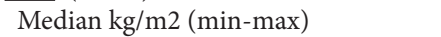 & $25.3(17.0-34.8)$ & $24.1(19.1-30.8)$ & $24.9(17.0-34.8)$ \\
\hline \multicolumn{4}{|l|}{ Albumin $(n=74)$} \\
\hline Median g/l (min-max) side effects + & $40(30-44)$ & $33(23-47)$ & $37(23-47)$ \\
\hline $\begin{array}{c}\text { side effects - } \\
\text { Creatinine clearance }(n=67)\end{array}$ & \multicolumn{2}{|c|}{ Creatinine clearance $(n=67)$} & $38(20-47)$ \\
\hline \multirow{2}{*}{$\begin{array}{r}\text { Median } \mathrm{ml} / \mathrm{min}(\mathrm{min}-\mathrm{max}) \\
\text { side effects + } \\
\text { side effects - }\end{array}$} & $103(49-134)$ & $108(60-148)$ & $104(49-148)$ \\
\hline & $120(28-175)$ & $90(46-140)$ & $100(28-175)$ \\
\hline \multicolumn{4}{|l|}{ Tumor location $(n=75)$} \\
\hline Esophageal & 1 & 1 & 2 \\
\hline Stomach & 19 & 15 & 34 \\
\hline Duodenal & 4 & 3 & 7 \\
\hline Small intestine & 11 & 13 & 24 \\
\hline Rectal & 6 & 1 & 7 \\
\hline Uncertain & 0 & 1 & 1 \\
\hline \multicolumn{4}{|l|}{ Metastases $(n=75)$} \\
\hline No metastasis & 41 & 0 & 41 \\
\hline Hepatic & 0 & 17 & 17 \\
\hline Extrahepatic & 0 & 17 & 17 \\
\hline - intraabdominal & 0 & 15 & 15 \\
\hline - pleural & 0 & 2 & 2 \\
\hline \multicolumn{4}{|l|}{ Tumor size $(n=75)$} \\
\hline$<5 \mathrm{~cm}$ & 6 & 3 & 9 \\
\hline $5-10 \mathrm{~cm}$ & 16 & 8 & 24 \\
\hline$>10 \mathrm{~cm}$ & 18 & 19 & 37 \\
\hline Missing data & 1 & 4 & 5 \\
\hline \multicolumn{4}{|l|}{ Risk classification $(n=75)$} \\
\hline Low & 0 & 0 & \\
\hline Intermediate & 6 & 0 & \\
\hline High & 35 & 34 & \\
\hline \multicolumn{4}{|l|}{ c-kit expression $(\mathrm{n}=75)$} \\
\hline CD 117 positive & $41(100 \%)$ & $34(100 \%)$ & $75(100 \%)$ \\
\hline \multicolumn{4}{|l|}{ Mutation status $(n=39)$} \\
\hline KIT exon 11 mutation & 15 & 11 & 26 \\
\hline KIT exon 9 mutation & 0 & 1 & 1 \\
\hline PDGFRA mutation & 1 & 0 & 1 \\
\hline Wild-type & 5 & 6 & 11 \\
\hline \multicolumn{4}{|l|}{ Initial indication for imatinib $(n=75)$} \\
\hline Neoadjuvant & 10 & 10 & 20 \\
\hline Adjuvant & 31 & 2 & 33 \\
\hline Recurrent & 0 & 10 & 10 \\
\hline Palliative & 0 & 12 & 12 \\
\hline \multicolumn{4}{|l|}{ Surgery / Margin $(n=75)$} \\
\hline Radical / R0 & 27 & 15 & 42 \\
\hline Intralesional / R1 & 14 & 14 & 28 \\
\hline Tumor reduction / R2 & 0 & 5 & 5 \\
\hline \multicolumn{4}{|c|}{ Time of follow-up from initiationof imatinib treatment $(n=75)$} \\
\hline Median months (min-max) & $51(8-107)$ & $44(4-105)$ & $48(4-107)$ \\
\hline Follow-up $(\mathrm{n}=75)$ & & & \\
\hline Alive, NED & 36 & 14 & 50 \\
\hline Alive, Stable disease & 1 & 5 & 6 \\
\hline Recurrence (reoperated) & $7(6)$ & $15(10)$ & $22(16)$ \\
\hline$\dagger$ from GIST & 4 & 12 & 16 \\
\hline$\dagger$ from other cause & 0 & 3 & 3 \\
\hline
\end{tabular}

$\mathrm{BMI}=$ Body mass index; NED $=$ No evidence of disease at the end of follow-up; $\uparrow=$ Dead 
Table 2. Details of the 30 patients with moderate, severe or life-threatening side effects from imatinib treatment.

\begin{tabular}{|c|c|c|c|c|c|c|c|c|c|}
\hline $\begin{array}{c}\text { Case } \\
\text { no }\end{array}$ & $\begin{array}{l}\text { Treat- } \\
\text { ment } \\
\text { setting }\end{array}$ & $\begin{array}{l}\text { Time to } \\
\text { side } \\
\text { effect } \\
\text { (months) }\end{array}$ & $\begin{array}{l}\text { Side effects if imatinib } \\
\text { type }\end{array}$ & grade & $\begin{array}{c}\text { Treat- } \\
\text { ment } \\
\text { (months) }\end{array}$ & $\begin{array}{l}\text { Stop of } \\
\text { imatinib }\end{array}$ & $\begin{array}{c}\text { Follow- } \\
\text { up } \\
\text { (months) }\end{array}$ & $\begin{array}{l}\text { Recur- } \\
\text { rence / } \\
\text { reopera- } \\
\text { tion }\end{array}$ & $\begin{array}{l}\text { Follow-up out- } \\
\text { come }\end{array}$ \\
\hline \multicolumn{10}{|c|}{ No metastatic disease } \\
\hline 1 & NeAd & $<1$ & deafness, dizziness & 2 & 4 & yes & 30 & no & alive, NED \\
\hline 2 & NeAd & $<1$ & $\begin{array}{l}\text { dermatitis, headache, muscle } \\
\text { cramps }\end{array}$ & 2 & 24 & no & 43 & no & alive, NED \\
\hline 3 & NeAd & $<1$ & nausea, vomiting, anorexia & 2 & 11 & no & 20 & no & alive, NED \\
\hline 4 & Ad & $<2$ & dermatitis, rash & 2 & 4 & yes & 60 & yes / no & $\dagger(\mathrm{GIST})$ \\
\hline 5 & Ad & $<1$ & dermatitis, rash, hepatopathia & 2 & 2 & yes & 100 & no & alive, NED \\
\hline 6 & Ad & $<2$ & dermatitis, rash, pruritus, edema & 2 & 3 & no & 105 & no & alive, NED \\
\hline 7 & Ad & $<1$ & $\begin{array}{l}\text { dermatitis, rash, pruritus, gastro- } \\
\text { intest bleeding }\end{array}$ & 2 & 2 & yes & 79 & no & alive, NED \\
\hline 8 & Ad & $<1$ & diarrhea & 2 & $<1$ & yes & 47 & no & alive, NED \\
\hline 9 & Ad & $<1$ & myalgia, muscle cramps, nausea & 2 & 37 & no & 41 & no & alive, NED \\
\hline 10 & Ad & $<1$ & muscle cramps, nausea & 2 & $<1$ & yes & 85 & no & alive, NED \\
\hline 11 & Ad & 4 & fatigue, dermatitis, rash & 2 & 5 & yes & 64 & no & alive, NED \\
\hline 12 & Ad & $<1$ & dermatitis, rash & 2 & 3 & yes & 51 & no & alive, NED \\
\hline 13 & Ad & $<1$ & edema, dermatitis, rash & 2 & 22 & no & 58 & no & alive, NED \\
\hline 14 & Ad & $<1$ & dermatitis, rash & 2 & $<1$ & yes & 18 & no & alive, NED \\
\hline 15 & Ad & $<1$ & dermatitis, rash & 2 & 12 & yes & 20 & no & alive, NED \\
\hline 16 & Ad & $>6$ & edema (angio- tung) & 3 & 11 & yes & 38 & no & alive, NED \\
\hline 17 & Ad & $<1$ & diarrhea, anorexia & 2 & 80 & no & 100 & yes / yes & ED \\
\hline \multicolumn{10}{|c|}{ Metastatic / Recurrent disease } \\
\hline 18 & NeAd & $<1$ & nausea, anorexia, edema & 2 & 97 & no & 101 & no & alive, NED \\
\hline 19 & NeAd & $<1$ & tumor perforation, acute surgery & 4 & 18 & no & 18 & no & alive, NED \\
\hline 20 & NeAd & $<2$ & dermatitis, rash & 2 & 4 & yes & 63 & yes / yes & ED \\
\hline 21 & NeAd & 18 & nausea, anorexia & 2 & 40 & noxa & 43 & no & alive, NED \\
\hline 22 & NeAd & 8 & neuropathia, edema, fatigue & 2 & 67 & yes & 88 & yes / yes & $\mathrm{ED}$ \\
\hline 23 & NeAd & $<3$ & dermatitis, rash & 2 & 7 & yes & 21 & no & $\dagger($ mesothelioma $)$ \\
\hline 24 & Pal & 27 & hypothyroidism & 2 & 29 & no & 36 & $\mathrm{PD}$ & $\dagger($ GIST) \\
\hline 25 & Pal & $<1$ & dermatitis, rash & 2 & 21 & no & 27 & yes / yes & alive, NED \\
\hline 26 & $\operatorname{Rec}$ & $<3$ & muscle cramps, nausea & 2 & 84 & no & 105 & no & alive, NED \\
\hline 27 & $\operatorname{Rec}$ & 30 & polyneuropathia, progressive & 2 & 36 & yes & 59 & no & alive, NED \\
\hline 28 & $\operatorname{Rec}$ & $<2$ & edema, dermatitis, rash & 2 & 46 & noxa & 97 & yes / yes & alive, NED \\
\hline 29 & Ad & $<1$ & agranulocytosis, sepsis & 4 & $52 \propto$ & yes & 81 & yes / yes & $\dagger($ ca coli $)$ \\
\hline 30 & Ad & $<1$ & edema, dermatitis, rash & 2 & 1 & yes & 83 & no & alive, NED \\
\hline
\end{tabular}

Follow-up refers to time from initiation of imatinib; NeAd = Neoadjuvant; $\mathrm{Ad}=$ adjuvant; $\mathrm{Rec}=$ recurrent disease; Pal = palliative PD = Persistant disease; NED = No evidence of disease at end of follow-up; ED = Evidence of disease; $\dagger=$ Dead

$a$ interrupted for three years, restarted after recurrence; $a$ (temporary) dose reduction 
Supplemental Table A. Clinical details of the 30 patients with moderate, severe or life-threatening side effects from imatinib treatment.

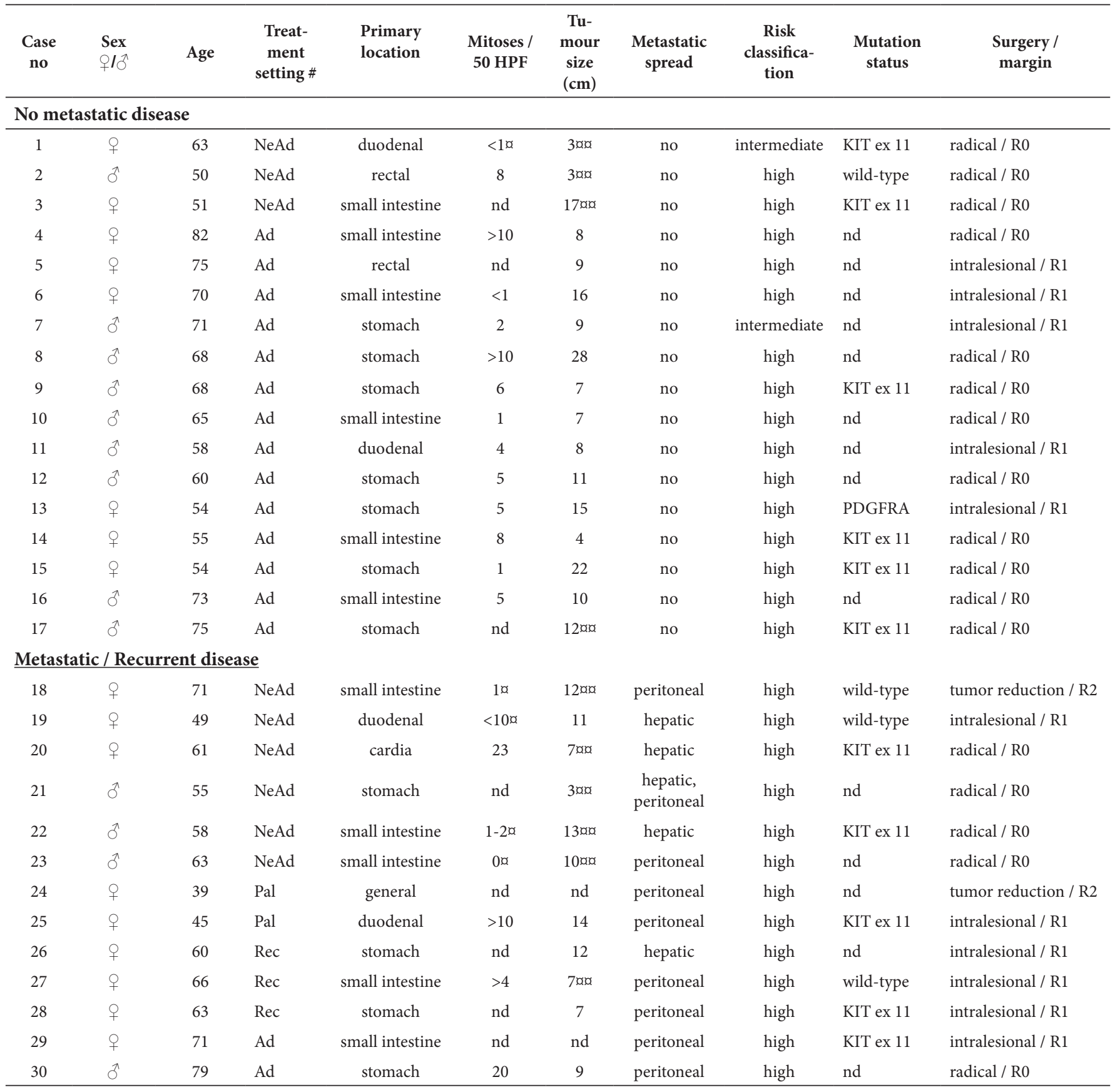

\# NeAd = Neoadjuvant; Ad = adjuvant; Rec = recurrent disease; $\mathrm{Pal}=$ palliative; $\mathrm{nd}$ = not determined $/$ no data available

a after (downstaging) treatment with imatinib, ax size based on $\mathrm{x}$-ray. 


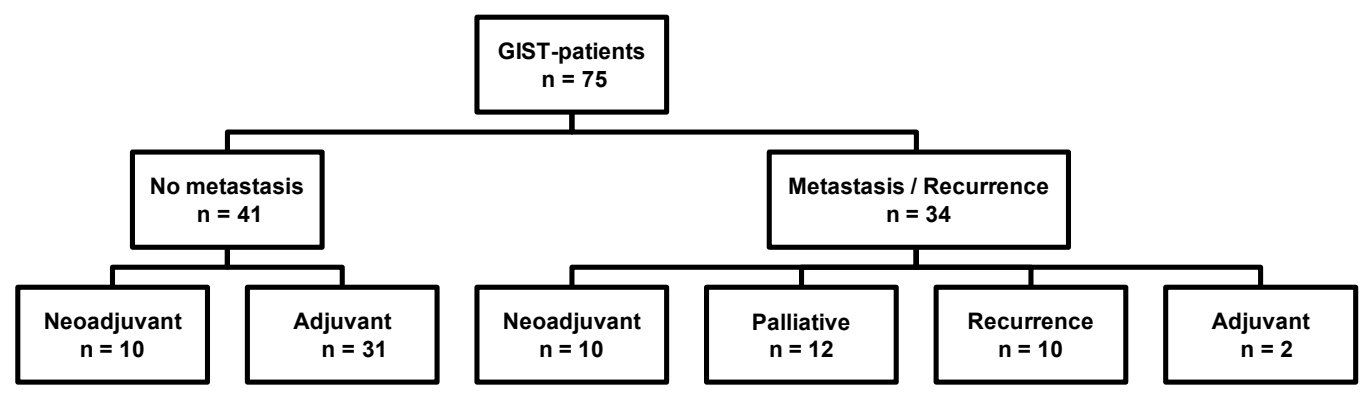

\begin{tabular}{|c|c|c|c|c|c|c|}
\hline Side effects $(n=30)$ & 3 & 14 & 6 & 3 & 3 & 1 \\
\hline \multicolumn{7}{|l|}{ Follow-up } \\
\hline Alive, NED ( $n=50)$ & 10 & 26 & 5 & 3 & 5 & 1 \\
\hline Alive, stable disease $(n=6)$ & - & 1 & 2 & - & 2 & 1 \\
\hline Recurrence / reoperation $(n=22 / 16)$ & - & $7 / 6$ & $4 / 4$ & $2 / 2$ & $8 / 3$ & $1 / 1$ \\
\hline$†$ from GIST $(n=16)$ & - & 4 & 1 & 9 & 2 & - \\
\hline$\dagger$ from other disease $(n=3)$ & - & - & 2 & - & 1 & - \\
\hline
\end{tabular}

Figure 1. Schematic illustration of the study cohort

\section{Association between side effects and favorable outcome}

The presence of side-effects was found to be associated with a favorable recurrence-free survival for the group of patients with metastatic or recurrent GIST (log rank test; $P=0.01$, Figure 2). No such differences were observed in the group of patients with localized disease, where the number of events was few (Supplemental Figure S1). The presence of side-effects was not found to be associated with differences in age, body weight, plasma albumin or creatinine clearance but there was a tendency to female dominance in the group of patients with metastatic or recurrent GIST $(P=0.078)$, and female patients had a favorable recurrence-free survival ( $P=0.01$, Figure 3 ). No differences in survival between men and women were found in the group of patients with localized disease (Supplemental Figure S2).

\section{Discussion}

The introduction of imatinib and other tyrosine kinase inhibitors has dramatically improved the prognosis for patients with high risk GIST. The treatment is generally considered to be well tolerated. However, recently attention has been drawn to a relatively high incidence of adverse events that may reduce the patient's adherence to and the clinical effectiveness of the imatinib treatment. It is important to be aware of the prevalence of side-effects and to offer supportive care to avoid interruption of treatment [16]. The objective of this retrospective study was to analyze the occurrence of moderate to severe or life-threatening side-effects and clinical outcome. Since some form of mild adverse event (i.e. grade 1) was reported in almost every case, we chose to limit our analysis to moderate-tosevere or life-threatening side-effects (grade 2 or higher), defined in accordance with the Common Terminology Criteria for Adverse
Events v4.0 (CTCAE). Forty percent of our patients complained of significant side-effects. For patients with metastatic or recurrent GIST, the presence of moderate to severe or life-threatening side-effects was associated with favorable recurrence-free survival. No such association was found for patients with localized GIST; however, for this group the strength of the analyses was limited by a relatively short follow-up time and few events.

The main weakness of this study is the lack of knowledge of the actual plasma concentration of imatinib. In GIST, higher exposure to imatinib has been found to predict a higher probability of therapeutic response, besides being correlated to the occurrence and number of side-effects [22]. However, determination of the plasma concentration of imatinib is still not used routinely in clinical practice and there are no practical guidelines for interpreting the concentration. A plasma concentration below $1,100 \mathrm{ng} / \mathrm{mL}$ has been associated with short time to disease progression in patients with unresectable/metastatic GIST [19] . The inter-patient variability in imatinib pharmacokinetics seems to be significant, and the trough level $\left(C_{\min }\right)$ has been significantly associated with albumin concentration, creatinine clearance and major gastrectomi but not to previous grades 3 to 4 toxicity in patients taken a standard dose of $400 \mathrm{mg}$ daily [18]. Except for patients with KIT exon 9 mutations, $400 \mathrm{mg}$ daily is the standard dose for treatment of high-risk GIST regardless of the patient's gender, age or body mass. A higher than standard dosage of imatinib has been associated with more severe sideeffects [17]. However, Blanke et al; reported no significant difference in objective response for patients treated with high dose imatinib but, similar to our findings, a favorable outcome for female patients. 

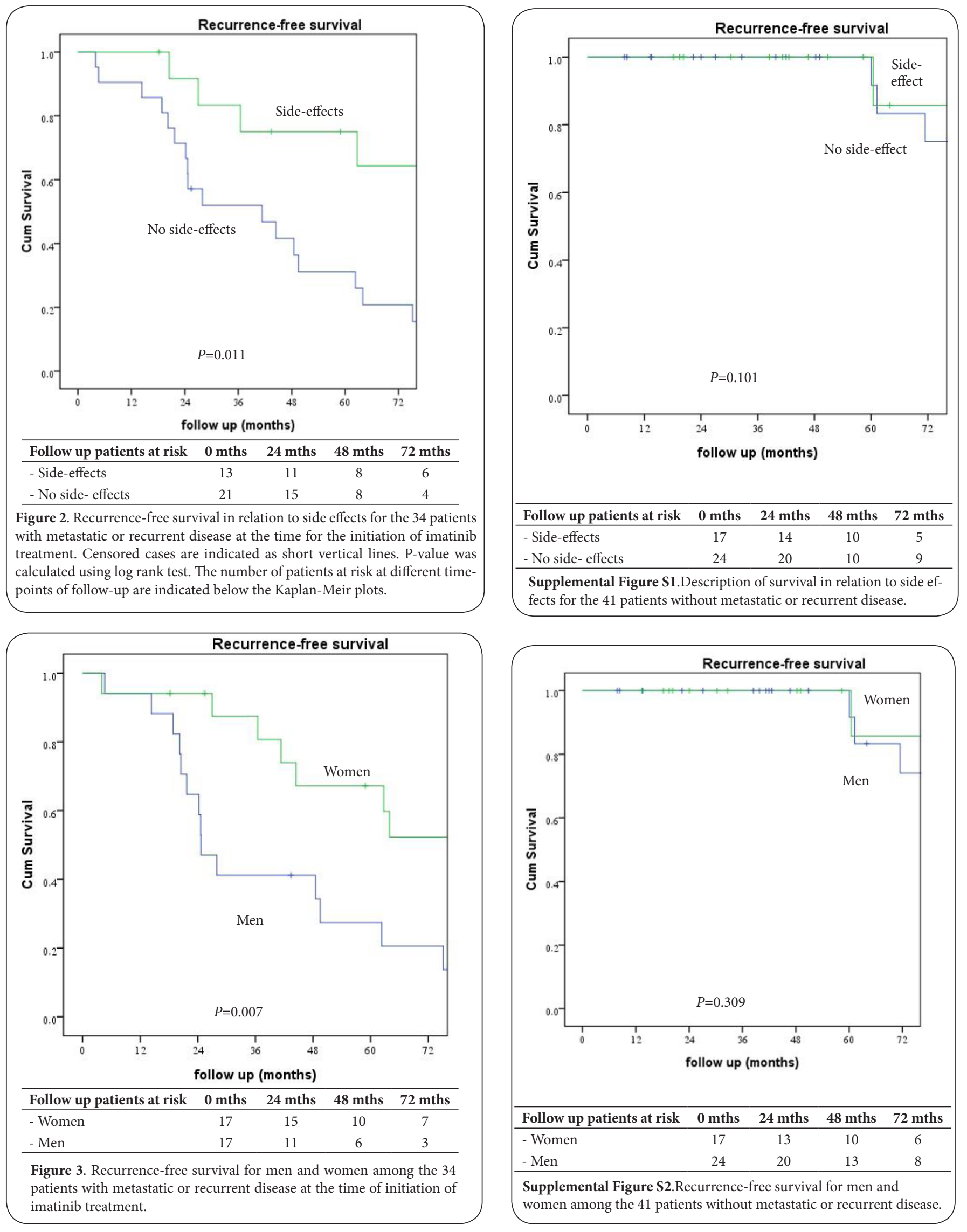
The observations of side effects and treatment response in GIST patients may be compared to similar studies in chronic myeloid leukemi (CML) for which imatinib treatment is the golden standard [23]. In CML, increased plasma concentrations of imatinib have been associated with a higher rate of complete molecular response [24]. In addition the plasma concentration was found associated with certain side effects [24]. Overall, slightly higher plasma concentrations were recorded in female compared to male patients [24]. Adherence to medication is another factor contributing to reduced treatment response and event free survival in CML $[25,26]$. In a study of pharmacy records for 4,043 patients reduced adherence to imatinib treatment was observed in CML as well as GIST patients [23,27].

While it is well established that patients with advanced GIST benefit from imatinib treatment, knowledge of how to optimize the dosage to obtain maximal effectiveness with a minimum of side-effects is limited. In this study we show that significant side effects from imatinib treatment are common and associated with a better outcome. This association likely reflects different plasma concentrations of imatinib. However, the lack of an association be tween body weight or BMI, plasma albumin or creatinine clearance and occurrence of side effects would argue against a simple dilution effect. Instead variations between patients related to factors such as adherence, drug absorption, pharmacokinetics and cellular uptake are expected to be of importance. Logically, the next step should be to perform a prospective follow-up study including plasma concentrations of imatinib and the main imatinib metabolites. Methods for the measurement of imatinib in plasma are currently not widely available for clinical practice. However, for the future, such methods are needed in order to evaluate how the plasma concentration of imatinib affects the event free survival and allow individualized tailoring of the dose to optimize outcome and minimize side-effects. Meanwhile our findings could be used in clinical practice in further supporting patients continued compliance to the medication when side effects are present. At the same time the patients have to be offered a close follow-up and proper management of side effects.

\section{Conflict of interest}

The authors declare that they have no conflict of interest.

\section{Acknowledgements}

We thank Fredrik Granath, Department of Medicine, Unit of

Clinical Epidemiology, for expert advices on the statistical

analyses. The study was supported financially by John Hedins

Stiftelse, the Swedish Research Council, the Swedish Cancer So-

ciety, Karolinska Institute and Stockholm County Council.

\section{Author information}

${ }^{2}$ Center for Molecular Medicine, Medical Genetics Unit, Karolinska Institutet, Karolinska University Hospital CMM L8:01, SE-171 76 Stockholm, Sweden.

\section{Article history}

Editor: Kosaku Iwatsubo, University of Medi-

cine and Dentistry of New Jersey, USA.

EIC: G.J. Peters, VU University Medical Center, Netherlands.

Received: 14-Feb-2012 Revised: 23-Apr-2012

Accepted: 25-Apr-2012 Published: 29-May-2012

\section{References}

1. Nilsson B, Bumming P, Meis-Kindblom JM, Oden A, Dortok A, Gustavsson $B$, et al.: Gastrointestinal stromal tumors: the incidence, prevalence, clinical course, and prognostication in the preimatinib mesylate era--a population-based study in western Sweden. Cancer 2005; 103;(4.);821-9. | Article | PubMed

2. Tran T, Davila JA, El-Serag HB: The epidemiology of malignant gastrointestinal stromal tumors: an analysis of 1,458 cases from 1992 to 2000. Am J Gastroenterol 2005; 100;(1.);162-8. | Article | PubMed

3. Pierie JP, Choudry U, Muzikansky A, Yeap BY, Souba WW, Ott MJ: The effect of surgery and grade on outcome of gastrointestinal stromal tumors. Arch Surg 2001; 136;(4.);383-9. I PubMed

4. Edmonson JH, Marks RS, Buckner JC, Mahoney MR: Contrast of response to dacarbazine, mitomycin, doxorubicin, and cisplatin (DMAP) plus GMCSF between patients with advanced malignant gastrointestinal stromal tumors and patients with other advanced leiomyosarcomas. Cancer Invest 2002; 20;(5-6.);605-12. | PubMed

5. DeMatteo RP, Lewis JJ, Leung D, Mudan SS, Woodruff JM, Brennan MF: Two hundred gastrointestinal stromal tumors: recurrence patterns and prognostic factors for survival. Ann Surg 2000; 231;(1.);51-8. | Article | PubMed Abstract | PubMed Central Full Text

6. Miettinen M, Makhlouf H, Sobin LH, Lasota J: Gastrointestinal stromal tumors of the jejunum and ileum: a clinicopathologic, immunohistochemical, and molecular genetic study of 906 cases before imatinib with long-term follow-up. Am J Surg Pathol 2006; 30;(4.);47789. | Article | PubMed

7. Casali PG, Jost L, Reichardt P, Schlemmer M, Blay JY: Gastrointestinal stromal tumors: ESMO clinical recommendations for diagnosis, treatment and follow-up. Ann Oncol 2008; 19 Suppl 2;(ii35-8). | Article | PubMed

8. Hirota S, Isozaki K, Moriyama $\mathrm{Y}$, Hashimoto $\mathrm{K}$, Nishida T, Ishiguro $\mathrm{S}$, et al.: Gain-of-function mutations of c-kit in human gastrointestinal stromal tumors. Science 1998; 279;(5350.);577-80. | PubMed

9. Fletcher CD, Berman JJ, Corless C, Gorstein F, Lasota J, Longley BJ, et al.: Diagnosis of gastrointestinal stromal tumors: a consensus approach. Int J Surg Pathol 2002; 10;(2.);81-9. | Article | PubMed

10. Miettinen $M$, Lasota J: Gastrointestinal stromal tumors--definition, clinical, histological, immunohistochemical, and molecular genetic features and differential diagnosis. Virchows Arch 2001; 438;(1.);1-12. | Article | PubMed

11. Joensuu H, Roberts PJ, Sarlomo-Rikala M, Andersson LC, Tervahartiala $P$, Tuveson D, et al.: Effect of the tyrosine kinase inhibitor STI571 in a patient with a metastatic gastrointestinal stromal tumor. $N$ Engl $\mathrm{J}$ Med 2001; 344;(14.);1052-6. | Article | PubMed

12. Demetri GD, von Mehren $M$, Blanke CD, Van den Abbeele AD, Eisenberg $B$, Roberts PJ, et al.: Efficacy and safety of imatinib mesylate in advanced gastrointestinal stromal tumors. N Engl J Med 2002; 347;(7.);472-80. | Article | PubMed

13. Dematteo RP, Ballman KV, Antonescu CR, Maki RG, Pisters PW, Demetri $\mathrm{GD}$, et al.: Adjuvant imatinib mesylate after resection of localised, primary gastrointestinal stromal tumour: a randomised, double-blind, placebo-controlled trial. Lancet 2009; 373;(9669.);1097-104. | Article | PubMed Abstract | PubMed Central Full Text

14. Eisenberg BL, Harris J, Blanke CD, Demetri GD, Heinrich MC, Watson JC, et al.: Phase II trial of neoadjuvant/adjuvant imatinib mesylate (IM) for advanced primary and metastatic/recurrent operable gastrointestinal stromal tumor (GIST): early results of RTOG 0132/ACRIN 6665. J Surg Oncol 2009; 99;(1.);42-7. | Article | PubMed Abstract | PubMed Central Full Text

15. McAuliffe JC, Hunt KK, Lazar AJ, Choi H, Qiao W, Thall P, et al.: A randomized, phase II study of preoperative plus postoperative imatinib in GIST: evidence of rapid radiographic response and temporal induction of tumor cell apoptosis. Ann Surg Oncol 2009; 16;(4.);910-9. | Article | PubMed

16. Joensuu H, Trent JC, Reichardt P: Practical management of tyrosine 
kinase inhibitor-associated side effects in GIST. Cancer Treat Rev 2011; 37;(1.);75-88. | Article | PubMed

17. Blanke CD, Rankin C, Demetri GD, Ryan CW, von Mehren M, Benjamin RS, et al.: Phase III randomized, intergroup trial assessing imatinib mesylate at two dose levels in patients with unresectable or metastatic gastrointestinal stromal tumors expressing the kit receptor tyrosine kinase: S0033. J Clin Oncol 2008; 26;(4.);626-32. | Article | PubMed Abstract | PubMed Central Full Text

18. Yoo C, Ryu MH, Kang BW, Yoon SK, Ryoo BY, Chang HM, et al.: Crosssectional study of imatinib plasma trough levels in patients with advanced gastrointestinal stromal tumors: impact of gastrointestinal resection on exposure to imatinib. J Clin Oncol 2010; 28;(9.);1554-9. | Article | PubMed

19. Demetri GD, Wang Y, Wehrle E, Racine A, Nikolova Z, Blanke CD, et al.: Imatinib plasma levels are correlated with clinical benefit in patients with unresectable/metastatic gastrointestinal stromal tumors. J Clin Oncol 2009; 27;(19.);3141-7. | Article | PubMed

20. Le Cesne A, Ray-Coquard I, Bui BN, Adenis A, Rios M, Bertucci F, et al.: Discontinuation of imatinib in patients with advanced gastrointestinal stromal tumours after 3 years of treatment: an open-label multicentre randomised phase 3 trial. Lancet Oncol 2010; 11;(10.);942-9. | Article | PubMed

21. Joensuu $\mathrm{H}$ : Risk stratification of patients diagnosed with gastrointestinal stromal tumor. Hum Pathol 2008; 39;(10.);1411-9. | Article | PubMed Abstract | PubMed Central Full Text

22. Widmer N, Decosterd LA, Leyvraz S, Duchosal MA, Rosselet A, DebiecRychter $M$, et al.: Relationship of imatinib-free plasma levels and target genotype with efficacy and tolerability. Br J Cancer 2008; 98;(10.);163340. | Article | PubMed Abstract | PubMed Central Full Text

23. Cortes JE, Egorin MJ, Guilhot F, Molimard M, Mahon FX: Pharmacokinetic/pharmacodynamic correlation and blood-level testing in imatinib therapy for chronic myeloid leukemia. Leukemia 2009; 23;(9.);1537-44. | Article | PubMed

24. Larson RA, Druker BJ, Guilhot F, O'Brien SG, Riviere GJ, Krahnke T, et al.: Imatinib pharmacokinetics and its correlation with response and safety in chronic-phase chronic myeloid leukemia: a subanalysis of the IRIS study. Blood 2008; 111;(8.);4022-8. | Article | PubMed

25. Yoshida C, Komeno T, Hori M, Kimura T, Fujii M, Okoshi Y, et al.: Adherence to the standard dose of imatinib, rather than dose adjustment based on its plasma concentration, is critical to achieve a deep molecular response in patients with chronic myeloid leukemia. Int J Hematol 2011; 93;(5.);618-23. | Article | PubMed

26. Ganesan P, Sagar TG, Dubashi B, Rajendranath R, Kannan K, Cyriac S, et al.: Nonadherence to imatinib adversely affects event free survival in chronic phase chronic myeloid leukemia. Am J Hematol 2011; 86;(6.);471-4. | Article | PubMed

27. Tsang J, Rudychev, Pescatore SL: Prescription compliance and persistency in chronic myelogenous leukemia (CML) and gastrointestinal tumor (GIST) patients (pts) on imatinib (IM). J Clin Oncol 2008; Vol 24, No. 18S (June 20 Supplement), 2006: 6119. | Article

\section{Citation:}

Åhlén J, Westerdahl J, Zedenius J, Bränström R, Larsson C and Nilsson IL: Side-effects from imatinib treatment of advanced GIST-associated with a better outcome. journal of Cancer Therapeutics and Research 2012, 1:11. http://dx.doi.org/10.7243/2049-7962-1-11 